\title{
Cystolithotripsy: Effect of Nursing Preparations on Patients' Pain and Satisfaction
}

\author{
Asmaa Hamdy Mohammed ${ }^{1}$, Zienab Abd-El-lateef Muhammad ${ }^{2}$, Medhat Ahmed Abdalla ${ }^{3}$, Rasha Ali \\ Ahmed ${ }^{4}$. \\ 1. Instructor, Medical-Surgical Nursing Department, Faculty of Nursing, Assiut University, Assiut, Egypt. \\ 2. Professor, Medical-Surgical Nursing Department, Faculty of Nursing, Assiut University, Assiut, Egypt. \\ 3. Professor, Professor of Urology, Faculty of Medicine, Assiut University, Assiut, Egypt. \\ 4. Lecturer, Medical-Surgical Nursing Department, Faculty of Nursing, Assiut University, Assiut, Egypt.
}

\begin{abstract}
Transurethral cystolithotripsy is the most common way to manage cystolithiasis. Aim of this study: Was to evaluate the effect of implementing nursing preparations on improving patients' pain and satisfaction. Patients and methods Randomized Control Study design was utilized to conduct this study. This study was carried out in the Urology and Nephrology Assiut University Hospital. A random sample of 60 adult patients of both sexes, the mean age of study group (51.20 \pm 11.73$)$ and the mean age of control group (49.36 \pm 12.49$)$. Patients were divided into two equal groups (study and control) 30 patients for each. Tools: Tool (I): Patient assessment sheet, tool (II): Pain numeric rating scale and tool (III): patient satisfaction with nursing care quality questionnaire. Results: Statistically significant differences were found between study and control groups post implementing nursing preparations as regard pain level and patients satisfaction. Conclusion: Significant pain improvement and high level of satisfaction were observed throughout implementation of the nursing preparations among the study group.
\end{abstract}

Key Words: Cystolithotripsy, Nursing Preparations \& Patients Satisfaction.

\section{Introduction}

Bladder stones account for a small amount of urinary stones. About $5 \%$ of urinary stones frequently seen in the elderly patients underlying many urological disorders. It is classified as stone migrated from upper urinary tract, primary idiopathic or secondary calculi (Malladad et al., 2018).

Bladder stones may not produce symptoms straight away. But if a stone irritate the bladder wall or blocks the flow of urine, signs and symptoms may include: lower abdominal pain, burning sensation during urination, frequent urination, difficulty urinating or interrupted urine flow and blood in urine (McAninch, 2013).

Most bladder stones can be managed with endoscopic surgery. The underlying cause, such as outlet obstruction, should also be addressed at the same time if possible. Cystolithotripsy can be achieved cystoscopically with most stone types (Tugcu et al., 2009).

Cystolithotripsy is a procedure of breaking up bladder stones into smaller pieces and remove them. An instrument called a cystoscope will be placed through urethra and into the bladder. The cystoscope has a camera that allows seeing the stone. An ultrasonic probe or laser fiber is then passed through the cystoscope and used to fragment the stone, stone fragments are flushed out of the bladder, the cystoscope is then removed (National kidney \& urologic diseases information website, 2015).

Complications of Cystolithotripsy may include: damaged urethra, perforated bladder, profuse bleeding, swollen urethra, scar tissue in the urethra, urinary tract infection, spasm of voiding muscles in bladder or an injured penis (Desai et al., 2015).

Preoperative care is the preparation and management of a patient prior to surgery. It includes both physical and psychological preparations. Patients who are physically and psychologically prepared for surgery tend to have better surgical outcomes. Preoperative teaching meets the patient's need for information regarding the surgical experience, which in turn may alleviate most of his or her fears (Mally et al., 2015). Nurses should pay attention to patient counseling so that patients and their families understand the surgical principles and possible postoperative complications. According to admission assessment form, nurse should conduct comprehensive assessment of patients to diagnose health problems such as hypertension, diabetes, and hepatitis. Acute urinary infection should be controlled before surgery and informed consent from patient or his family must be obtained before the procedure (Pritchard, 2012).

Nurse should be aware of the most common complications that can occur to those patients including: postoperative bleeding, urinary tract infection, dysuria, urinary bladder perforation and swollen urethra or damaged urethra. When any of these complications occur, the nurse should ensure that the appropriate actions are taken. Early detection and rapid response are key to ensure safe nursing practice and positive patient outcomes and give the 
patient verbal and written instructions to follow at home (Desai et al., 2015).

Patient satisfaction is a critical component in the measurement of quality of care. Nursing service is one of the most important components of hospital service. The level of patient satisfaction with nursing care is an important indicator of quality of care provided in hospitals. Patient satisfaction is a term that can be interpreted differently by patients and its meaning can also differ form one patient to another. A satisfied patient is more willing to recommend the hospital to provide its care to others (Andaleeb, 2011).

\section{Significance of the study}

Through the clinical experience the researcher observed that patients undergoing transurethral cystolithotripsy need special nursing preparations and instructions to improve their outcomes. This study was conducted to provide patients with nursing preparations in an attempt to improve patients' satisfaction as possible.

\section{Aim of this study}

Evaluate the effect of implementing nursing preparations on improving pain and satisfaction of patients undergoing cystolithotripsy.

Hypothesis

To fulfill the aim of the study the following research hypothesis was formulated:-

Pain and satisfaction will be improved in patients of the study group than the control group.

Research design

Randomized Control Study design was utilized to conduct this study.

(Single number $=$ Study group) and (Double number $=$ Control group).

\section{Setting}

The study was conducted in the Urology and Nephrology Assiut University Hospital.

\section{Subjects}

Sixty adult patients of both sexes from selected area. Age ranges from 18 to 65 years. Patients were divided randomly into two equal groups (study and control) 30 patients for each (Single number $=$ Study group and Double number $=$ Control group). The study group received the nursing preparations while the control group received the routine hospital care.

Study tools

Three tools were utilized to collect data for this study. It included the following:

Tool (I): Patient assessment sheet: It consisted of three parts that covered the following information:

Part (1): Demographic data of patient: name, age, sex, level of education and marital status.
Part (2): Medical data: medical diagnosis, medical history, signs and symptoms of bladder stones and patient's vital signs (temperature, pulse, respiration and blood pressure).

Part (3): Laboratory investigations: of the patient that included the following: complete blood picture, prothrombin time, creatinine, international normalized ratio, hepatitis $\mathrm{C}$ virus, and hepatitis $\mathrm{B}$ virus.

Tool (II): Pain numeric rating scale

It was adopted from McCaffery et al., (1993) to assess pain intensity at the surgery site and around it after the procedure. A scale of 0 to 10 , with 0 being no pain at all and 10 being the worst pain imaginable.

\begin{tabular}{|c|c|}
\hline Pain & Rating scale \\
\hline No pain & 0 \\
\hline Mild & $1-3$ \\
\hline Moderate & $4-6$ \\
\hline Severe & $7-10$ \\
\hline
\end{tabular}

Tool (III): Patient satisfaction with nursing care quality questionnaire (PSNCQQ):

Patient satisfaction with nursing care quality questionnaire was derived from the Patient Judgment of Hospital Quality Questionnaire.

A multidisciplinary research team at the Hospital Corporation of America developed the original Patient Judgment of Hospital Quality Questionnaire instrument Laschinger et al., (2005). Questions designed to measure: satisfaction with the overall quality of care during the hospital stay, overall quality of nursing care, and intention to recommend the hospital to family and friends. The original tool consisted of 9 scales: nursing and daily care, hospital environment, medical care, information, admissions, discharge and billing, overall quality of care and services, recommendations and intentions, and overall health outcomes.

\section{Methods}

\section{Ethical approval}

An official approval and administration permission were obtained from the head of the urology department to collect the necessary data. Each patient was informed with the purpose of the study to gain cooperation. The researcher emphasized that the participation was voluntary, confidentiality of patients data was assured, privacy of patients was ascertained and there was no hazards. Verbal consent was obtained from each patient to his or her contribution in the present study.

\section{Validity and reliability}

The study tools were reviewed by a panel of medicalsurgical nursing and urology experts (5 experts; 3 medical-surgical nursing and 2 urology staff).

Coefficient correlation was used to assess reliability (0.87). 


\section{Pilot study}

A pilot study on (10\%) 6 patients was conducted during March, 2018. It's purpose was to assess the feasibility of the study and clarity of the data collection tools. It also helped to estimate the time needed for filling the questionnaire. The data obtained from the pilot study was analyzed and modifications were made. Patients involved in the pilot study weren't included in the main study.

Procedure: The study was carried out on three phases

\section{1- The preparatory phase}

Preparation of tools for data collection and the designed nursing preparations were done during this phase. To facilitate the implementation of the nursing preparations for patients undergoing cystolithotripsy, researcher prepared the teaching places, teaching aids and media (pictures and handouts).This was followed by arranging for the teaching schedule based on the contents of the nursing preparations booklet and time availability.

\section{2- Implementation phase}

- Each patient was interviewed individually immediately after admission and daily till discharge.

- Oral consent was obtained.

- Once permission was granted to proceed with the proposed study, the researcher initiated data collection.

- At initial interview the researcher introduced herself to initiate line of communication, explain the nature and purpose of the study to patients.

- Patients were randomly enrolled in the present study as study and control groups (Single number = Study group) and (Double number $=$ Control group).

- Each patient involved in the study was assessed for (tool I). The study was carried out at morning and after-noon shifts.

- Each patient was received 2 sessions by the researcher, each session lasted from 30- 45 minutes.

- Patients who constituted the control group were exposed to routine nursing preparations, while patients who constituted the study group were exposed to the designed nursing preparations.

- The researcher explained and discussed with patients preoperative nursing care, postoperative nursing care, and home instructions.

\section{Preoperative nursing preparations for patients}

The nursing preparations had been implemented for the study group to elaborate the impact of implementing nursing preparations on improving pain and satisfaction. The nursing preparations for patients were developed by the researcher based on the review of relevant literature. Reinforcement of teaching was performed according to patients' needs to ensure their understanding. Each patient in the study group received a copy of the nursing preparations booklet. The researcher used pictures for illustration, and diagram to educate the patient. Preoperative preparations included the following:

- Physical and psychological preparations.

- Diet: The nurse instructs the patient to fast 6-8 hours prior to surgery. Patient may, however, be able to drink clear fluids up to two hours before surgery.

- Smoking: The nurse instructs the patient to avoid smoking after midnight the night before surgery as smoking can delay healing.

- Bowel: The nurse instructs the patient to empty bowel to prevent constipation after surgery.

- Medications: The nurse instructs the patient to stop any medications that cause bleeding such as aspirin, non-steroid anti-inflammatory drugs and other blood thinners for 7 days before surgery. Nurse gives the patient appropriate oral or intravenous antibiotics prior surgery based on findings of the preoperative urine culture and sensitivity tests.

- Anesthesia: The nurse instructs the patient about the type of anesthesia for transurethral cystolithotripsy (spinal anesthesia and some times general anesthesia according to the patient condition). Intraoperative position includes laying the patient on his or her back with knee flexed.

- Operation: Teach patient that transurethral cystolithotripsy is a procedure of breaking up bladder stones into smaller pieces and remove them.

- Breathing exercise: Advise patient before surgery about breathing exercise to keep lung clear of fluid and prevent chest infection.

- Leg exercise: Teach patient about pedaling the feet, bending the knee and do not cross legs as this may cause obstruction to the blood circulation.

\section{Postoperative nursing care and home instructions}

- Assess and maintain cardiopulmonary status, neurological status and comfort level of the patient, close observation of urine output and color changes, measure and record amount of urine to maintain patency of catheter drainage, and assess the patient's pain level using pain scale.

- Urinary catheter irrigation was performed until urine return clear from blood clots, mucous or bleeding.

- Catheter care was performed to early detection and prevention of urinary tract infection through the following: properly fix catheter as its height must not exceed the level of symphysis pubis to prevent retrograde infection, ongoing liberalization of the catheter to relieve bladder pressure as this reduce the reflux of urine to the pelvis, encourage patient 
to drink more than $3000 \mathrm{ml}$ of water per day and instruct patient to keep the perineum area always clean to prevent urinary tract infection.

- Patients were provided with verbal and written instructions to follow at home as avoid heavy lifts or straining for 2 weeks following surgery, avoid driving while they are taking pain medications as it cause dizziness and sleep, and discuss with the patient catheter care at home and signs and symptoms of urinary tract infection that should be reported to the physician or nurse as unexplained fever, bright red urine, inability to pass urine, significant leakage around catheter or pain that is not controlled by prescribed medications.

\section{3- Evaluation phase}

- After implementation of the nursing preparations for patients, pain was assessed post transurethral cystolithotripsy for both study and control groups using (tool II) before discharge.

- Tool (III) was applied to the study and control groups before discharge to assess satisfaction level with the overall quality of care during the hospital stay, overall quality of nursing care, and intention to recommend the hospital to family and friends.

\section{Ethical considerations}

- Research proposal was approved from Ethical Committee in the Faculty of Nursing.
- There was no risk for study subject during application of the research.

- The study followed common ethical principles in clinical research.

- Oral consent was obtained from patients or guidance who are willing to participate in the study, after explaining the nature and purpose of the study.

- Confidentiality and anonymity were assured.

- Study subject had the right to refuse to participate or withdraw from the study without any rational at any time.

\section{Statistical analysis}

Data entry and statistical analysis were done using SPSS version, 20 statistical software package. Data were presented using descriptive statistics in the form of frequencies and percentages for qualitative variables, mean and standard deviations for quantitative variables. Independent t-test and cross tabulation was used to the inter-relationships among quantitative variables. The level of significance for this study was set as $(p<0.05)$ to detect any difference found in the data available.

\section{Results}

Table (1): Comparison between demographic characteristics of the study and control groups $(n=60)$.

\begin{tabular}{|c|c|c|c|c|c|}
\hline \multirow[t]{2}{*}{ Patients } & \multicolumn{2}{|c|}{$\begin{array}{l}\text { Study } \\
(n=\mathbf{3 0})\end{array}$} & \multicolumn{2}{|c|}{$\begin{array}{c}\text { Control } \\
(n=30)\end{array}$} & \multirow[t]{2}{*}{ p.v } \\
\hline & No. & $\%$ & No. & $\%$ & \\
\hline \multicolumn{6}{|l|}{ Age: } \\
\hline $18<30$ yrs & 0 & 0.0 & 2 & 6.7 & \multirow{5}{*}{$0.477 \mathrm{~ns}$} \\
\hline $30<40$ yrs & 5 & 16.7 & 3 & 10.0 & \\
\hline $40<50$ yrs & 7 & 23.3 & 7 & 23.3 & \\
\hline $50<60$ yrs & 7 & 23.3 & 10 & 33.3 & \\
\hline $60<65$ yrs & 11 & 36.7 & 8 & 26.7 & \\
\hline Mean \pm SD & \multicolumn{2}{|c|}{$51.20 \pm 11.73$} & \multicolumn{2}{|c|}{$49.36 \pm 12.49$} & \\
\hline \multicolumn{6}{|l|}{ Sex: } \\
\hline Male & 29 & 96.7 & 29 & 96.7 & \multirow{2}{*}{$0.754 \mathrm{~ns}$} \\
\hline Female & 1 & 3.3 & 1 & 3.3 & \\
\hline \multicolumn{6}{|l|}{ Marital status: } \\
\hline Single & 4 & 13.3 & 2 & 6.7 & \multirow{2}{*}{$0.335 \mathrm{~ns}$} \\
\hline Married & 26 & 86.7 & 28 & 93.3 & \\
\hline \multicolumn{6}{|l|}{ Educational level: } \\
\hline Illiterate & 9 & 30.0 & 14 & 46.7 & \multirow{5}{*}{$0.324 \mathrm{~ns}$} \\
\hline Read and write & 8 & 26.7 & 4 & 13.3 & \\
\hline Primary school & 3 & 10.0 & 5 & 16.7 & \\
\hline Secondary school & 7 & 23.3 & 3 & 10.0 & \\
\hline University & 3 & 10.0 & 4 & 13.3 & \\
\hline
\end{tabular}


Table (2): Distribution of studied sample (study and control groups) regarding medical data $(\mathrm{n}=60)$.

\begin{tabular}{|c|c|c|c|c|c|}
\hline \multirow{2}{*}{ Medical data } & \multicolumn{2}{|c|}{ Study $(n=30)$} & \multicolumn{2}{|c|}{ Control $(n=30)$} & \multirow{2}{*}{ p.v } \\
\hline & No. & $\%$ & No. & $\%$ & \\
\hline \multicolumn{6}{|l|}{ Medical diagnosis } \\
\hline Solitary urinary bladder stone & 21 & 70.0 & 23 & 76.7 & \multirow{3}{*}{$0.826 \mathrm{~ns}$} \\
\hline Recurrent urinary bladder stone & 6 & 20.0 & 5 & 16.7 & \\
\hline Renal and bladder stones & 3 & 10.0 & 2 & 6.7 & \\
\hline \multicolumn{6}{|l|}{ Chronic diseases } \\
\hline Cardiovascular disease & 1 & 16.7 & 6 & 66.7 & \multirow{3}{*}{$0.065^{*}$} \\
\hline Endocrine disease & 5 & 83.3 & 2 & 22.2 & \\
\hline Other (renal disease) & 0 & 0.00 & 2 & 11.1 & \\
\hline \multicolumn{5}{|c|}{ Sign and symptoms (filling) (more than one) } & \multirow{4}{*}{$0.006^{*}$} \\
\hline Frequency of urination & 13 & 43.3 & 6 & 20 & \\
\hline Urgency & 13 & 43.3 & 6 & 20 & \\
\hline Lower abdominal pain & 14 & 46.7 & 10 & 33.3 & \\
\hline \multicolumn{5}{|c|}{ Sign and symptoms (voiding) (more than one) } & \multirow{4}{*}{$0.039 *$} \\
\hline Urinary retention & 7 & 24.1 & 7 & 24.1 & \\
\hline Burning sensation during urination & 5 & 17.2 & 4 & 13.3 & \\
\hline Hematuria & 9 & 31.0 & 19 & 53.3 & \\
\hline
\end{tabular}

Table (3): Relation between demographic data of studied patients and their satisfaction with the overall quality of nursing care.

\begin{tabular}{|c|c|c|c|c|c|c|c|c|c|}
\hline \multirow{3}{*}{$\begin{array}{c}\text { Demographic } \\
\text { data }\end{array}$} & \multicolumn{4}{|c|}{ Study $(n=30)$} & \multicolumn{4}{|c|}{$\operatorname{Control}(n=30)$} & \multirow{3}{*}{ p.v } \\
\hline & \multicolumn{2}{|c|}{ Satisfied } & \multicolumn{2}{|c|}{ Unsatisfied } & \multicolumn{2}{|c|}{ Satisfied } & \multicolumn{2}{|c|}{ Unsatisfied } & \\
\hline & $\mathbf{N}$ & $\%$ & $\mathbf{N}$ & $\%$ & $\mathbf{N}$ & $\%$ & $\mathbf{N}$ & $\%$ & \\
\hline \multicolumn{10}{|l|}{ geA } \\
\hline $18<30$ yrs & 0 & 0.0 & 0 & 0.0 & 1 & 3.3 & 1 & 3.3 & \multirow{5}{*}{$0.373 \mathrm{~ns}$} \\
\hline $30<40$ yrs & 4 & 26.7 & 1 & 3.3 & 0 & 0 & 3 & 10.0 & \\
\hline $40<50 \mathrm{yrs}$ & 1 & 6.7 & 6 & 40.0 & 0 & 0 & 7 & 23.3 & \\
\hline $50<60 y r s$ & 4 & 26.7 & 3 & 20.0 & 2 & 6.7 & 8 & 26.7 & \\
\hline $60-65 y r s$ & 6 & 40.0 & 5 & 33.3 & 1 & 3.3 & 7 & 23.3 & \\
\hline \multicolumn{7}{|l|}{ Sex } & \multicolumn{3}{|c|}{ Sex } \\
\hline Male & 15 & 50 & 14 & 46.7 & 4 & 3.3 & 25 & 83.3 & \multirow{2}{*}{$0.768 \mathrm{~ns}$} \\
\hline Female & 0 & 0.0 & 1 & 3.3 & 0 & 0 & 1 & 3.3 & \\
\hline \multicolumn{5}{|l|}{ Educational level } & & & & \multicolumn{2}{|c|}{ Marital status } \\
\hline Illiterate & 4 & 26.7 & 5 & 33.3 & 1 & 3.3 & 13 & 43.3 & \multirow{5}{*}{$0.325 \mathrm{~ns}$} \\
\hline Read and write & 5 & 33.3 & 3 & 20.0 & 1 & 3.3 & 3 & 10.0 & \\
\hline Primary school & 1 & 6.7 & 2 & 13.3 & 0 & 0 & 5 & 16.7 & \\
\hline Secondary school & 2 & 13.3 & 5 & 33.3 & 1 & 3.3 & 2 & 6.7 & \\
\hline University & 3 & 20.0 & 0 & 0.0 & 1 & 3.3 & 3 & 10.0 & \\
\hline
\end{tabular}




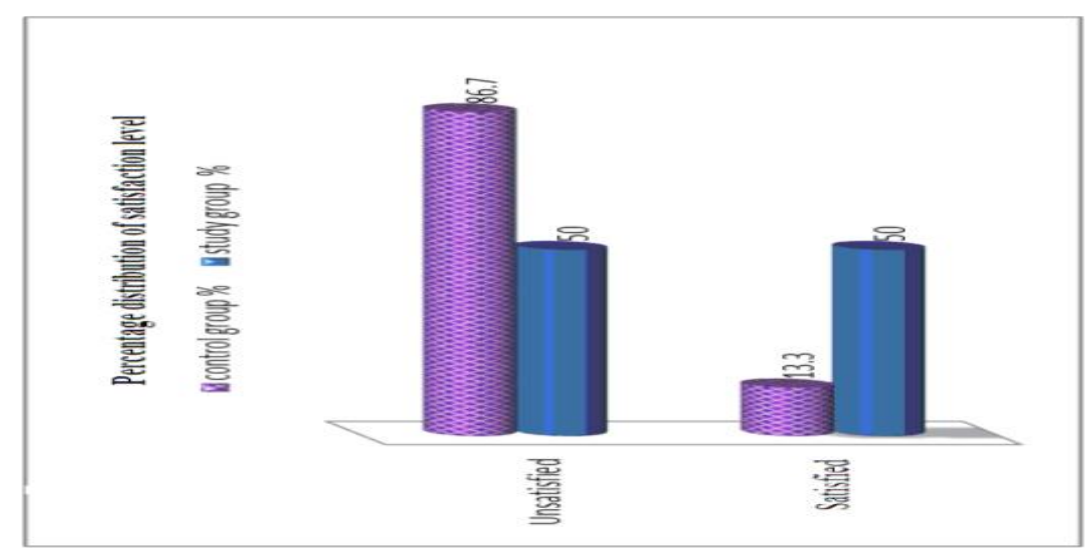

Figure(1): Satisfaction level among the study and control groups after implementation of nursing preparations.

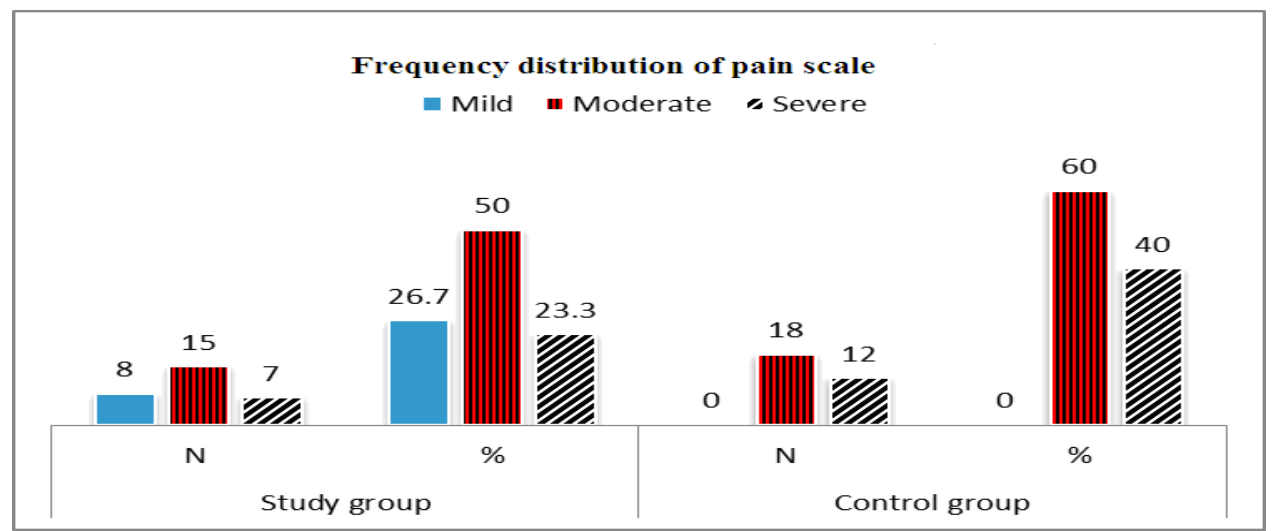

Figure (2): Comparison between the study and control groups regarding post- transurethral cystolithotripsy pain levels.

Table (1): This table reveals that, the majority of patients were males in both study and control groups $(96.7 \%)$ with mean age $(51.20 \pm 11.73,49.36 \pm 12.49)$ respectively. The majority of the study and control groups were married $(86.7 \%$ and $93.3 \%)$ respectively. Regarding educational level $30.0 \%$ of study group and $46.7 \%$ of control group were illiterate.

Table (2): This table reveals that, as regard medical diagnosis $(70 \%$ and $76,7 \%)$ of patients of the study group and control group were having solitary urinary bladder stone respectively. As regard chronic diseases $(83,3 \%)$ in the studied group had endocrine disease and $(16,7 \%)$ had cardiovascular disease, while in the control group $(66,7 \%)$ had cardiovascular disease and $(22,2 \%)$ had endocrine disease. Statistical significance difference (P.value 0.006) was found between study and control groups as regard filling signs and symptoms. Statistical significance difference (P.value 0.039) was found between study and control groups as regard voiding signs and symptoms.

Table (3): This table shows that, there were non statistical significance relations between the study and control groups as regard demographic data of patients (age, sex and educational level) and patients satisfaction with the overall quality of nursing care (p. value $0.374,0.768,0.325$ ) respectively.

Figure (1): This figure illustrated that half of the study group patients were satisfied with the overall quality of nursing care post implementation of nursing preparations while $(13.3 \%)$ of patients of control group were satisfied with the overall quality of nursing care, this illustrated statistical significance difference with (P-value 0.002).

Figure (2): This figure illustrated that a statistical significant difference between the study and control groups regarding post transurethral cystolithotripsy pain.

\section{Discussion}

The present study clarified that the incidence of urinary bladder stones was higher in age group between 50 to 65 years. This finding consistent with Newman, (2017) who mentioned that bladder stones are most common in the age of 50 years. Sharma et al., (2011) mentioned that urinary bladder stones are 
most common above the age of 50 years and they account for approximately $5 \%$ of all urinary stones. In this study the incidence of bladder stones among males was more than females which is consistent with most of the studies Nagaraj, (2018) who revealed that bladder stones were present among males more than females. Also, Stav \& Dwyer, (2012) mentioned that more males have urinary bladder stones as compared to females. This can be explained by the fact that urinary bladder stones in females present due to wide urethra so that small stones are passed before giving symptoms and also the usual cause of bladder stone is the bladder outlet obstruction such as benign prostatic hyperplasia and stricture urethra in males.

The present study showed that the majority of patients in the study and control groups had solitary urinary bladder stone. This study finding was supported by Hashmi et al., (2014) who reported that the stones were solitary urinary bladder stone in most of patients and multiple small renal and bladder stones in one third of patients.

The present study showed that frequency of urination, dysuria, urgency, suprapubic pain, hematuria, and retention of urine were the most common signs and symptoms appeared on patients with urinary bladder stones. The previous result supported by Hashmi et al., (2014) who mentioned that patients in his study was presented with different urological symptoms dysuria, frequency of urine, urgency, pyuria, suprapubic pain, hematuria and retention of urine.

Patient satisfaction is the popular way of evaluating nursing practice in most countries. Patient satisfaction has become a critical component in the measurement of quality of care. The level of patient satisfaction with nursing care is an important indicator of quality of care provided in hospitals Laschinger et al., (2005).

The present study showed that, after implementation of nursing preparations, the study group had higher levels of satisfaction with the overall quality of nursing care than the control group. This result supported the study hypothesis which suggested that the satisfaction level of the study group patients after implementation of nursing preparations will be higher than the control group. This result was in agreement with Rajeswarit, (2011) who reported that satisfaction level with nursing care of the study group patients was higher than the control group.

The present study showed that, there are no statistical significant relations between patients satisfaction and demographic characteristics (age, sex and educational level). This result was in agreement with Sen, (2017) who reported that there are no significant relations between satisfaction of patients and demographic characteristics except age group, there is statistical difference in patients satisfaction and quality of nursing care.

The present study showed that the study group experienced low pain levels post transurethral cystolithotripsy than the control group. This could be explained by the importance of appropriate nursing preparations, care and teaching.

This result was in agreement with Biardeau et al., (2017) who believed that the quality of medical information provided could play a major role in patient perceptions of anxiety, pain, or embarrassment.

\section{Conclusion}

Based upon the results of the current study, it could be concluded that:

Application of the designed nursing preparations for patients undergoing transurethral cystolithotripsy significantly improved their outcomes; significantly increase level of patients satisfaction with nursing care, and minimized pain levels.

\section{Recommendations}

Based on the previous findings of present study, the following recommendations are suggested:

- Action plan to educate patients who are undergoing transurethral cystolithotripsy about pre and post-operative care.

- Simple illustration booklet should be available for all patients to provide them with simple explanation about preoperative and postoperative care .

- Replication of the current study on larger probability sample is recommended to achieve generalizability and wider utilization of the nursing preparations.

- Emphasize the importance of regular follow-up at regular times.

\section{References}

1- Andaleeb S., (2011): Service quality and patient satisfaction, A study of Hospitals in a developing country, Soc Sci Med, Vol., 52, Pp. 1359-1370.

2- Biardeau X., Lam O., Campeau L., \& Corcos J., (2017): Prospective evaluation of anxiety, pain, and embarrassment associated with cystoscopy and urodynamic testing in clinical practice, Original research, Canadian Urological Association, Vol. 11, Issues 3-4, Pp. 104- 111.

3- Desai D., Wilcox D., Koyle M., \& Godbole P., (2015): Pediatric urology: surgical complications and management book, cystoscopy and cystoscopic interventions, $2^{\text {nd }}$ ed, P. 228. 
4- Hashmi S., ullah Khan I., \& Khan S., (2014): The Efficacy, Safety and Complications of Litholapaxy for Bladder Stones, Vol. 8, No.4.

5- Laschinger H., Hall L., Pederson S., \& Almost J., (2005): A psychometric analysis of patient satisfaction with nursing care quality questionnaire, an actionable approach to measuring patient satisfaction, J Nurse Care quality Vol. 20, Pp. 220-230.

6- Mally A., Kenner C., Kim T., \& Blakeney B., (2015): The role of the nurse and the preoperative assessment in patient transition, AORN journal, Vol.102, No.2, P.181.

7- Malladad N., Darshan A., \& Manjunath., (2018): Clinical study and management of vesical calculus, International Surgery Journal, Vol. 5, Issue 4 , P.128.

8- McAninch J., (2013): Smith \& Tanagho's General Urology, Urinary stone disease, $18^{\text {th }}$ ed. The McGraw-Hill Companies, http://www.accessmedicine.com.

9- McCaffrey M., Pasero C., \& Beebe A., (1993): Teaching patients to use a numerical pain-rating scale, The American Journal of Nursing, Vol.99, No. 12, P. 22.

10- Nagara J., Malladad, Darshan A., Manjunath R., \& Radhakrishna, (2018): Clinical study and management of vesical calculus, International Surgery Journal, Vol. 5, Issue 4 , P. 128.

11- National kidney \& urologic diseases information website, (2015): Cystoscopy and Ureteroscoy,

http://kidney.niddk..gov/kudiseases/pubs/cystos copy.

12- Newman, (2017): All about bladder stones, Medical News Today, MediLexicon, https://www.medicalnewstoday.com/articles/18 4998.php.

13- Pritchard M., (2012): Pre-operative assessment of elective surgical patients, Nursing Standard, National Institution of Health, Vol. 26, No. 30, Pp. 51-56.

14- Rajeswarit, (2011): Study to assess patient's satisfaction with quality of nursing care, International Journal of Advanced Research, Vol. 7, No.5, P.45.

15- Sen S., (2017): A study to assess patient's satisfaction with quality of nursing care in neuromedical department in selected hospital of Haryana, International Journal of Advanced Research, Vol. 7, No.5, Pp.112-123.
16- Stav K., \& Dwyer P., (2012): Urinary bladder stones in women, Obstetatric Gynecology Survery, Vol. 67, Pp. 715-725.

17- Sharma R., Curt E., David Y., \& Gelman M., (2011): Urinary bladder stones, The Journal of Emergency Medicine, Vol. 41, No. 2, Pp. 185186.

18- Tugcu V., Polat H., Ozbay B., Gurbuz N., Eren G., \& Tasci A., (2009): Percutaneous versus transurethral cystolithotripsy, Journal of endourology, Vol.23, No. 2, Pp. 237-241. 